\title{
Natural magnetite nanoparticles from an iron-ore deposit: size dependence on magnetic properties
}

\author{
M. L. Rivas-Sánchez ${ }^{1}$, L. M. Alva-Valdivia ${ }^{1,4}$, J. Arenas-Alatorre ${ }^{2}$, J. Urrutia-Fucugauchi ${ }^{1}$, M. Perrin ${ }^{3}$, \\ A. Goguitchaichvili ${ }^{4}$, M. Ruiz-Sandoval ${ }^{5}$, and M. A. Ramos Molina ${ }^{5}$ \\ ${ }^{1}$ Laboratorio de Paleomagnetismo, Instituto de Geofísica, Universidad Nacional Autónoma de México, 04510 Mexico D. F., Mexico \\ ${ }^{2}$ Instituto de Física, Universidad Nacional Autónoma de México, 04510 Mexico D. F., Mexico \\ ${ }^{3}$ Géosciences Montpellier, Université Montpellier II, 34095 Montpellier Cedex 05, France \\ ${ }^{4}$ Laboratorio Interinstitucional de Magnetismo Natural, Instituto de Geofisica, Sede Michoacan, \\ Universidad Nacional Autonoma de Mexico, Campus Morelia, Mexico \\ ${ }^{5}$ Dirección General y Dirección de Tecnología, Consorcio Minero Benito Juárez, Peña Colorada, \\ S. A. de C. V., Av. del trabajo No. 1000, Manzanillo, Colima, Mexico
}

(Received September 12, 2007; Revised July 20, 2008; Accepted July 21, 2008; Online published January 23, 2009)

\begin{abstract}
We report on the discovery of magnetite nanoparticles ranging in size from 2 to $14 \mathrm{~nm}$ in the mineralized zones of the Peña Colorada iron-ore deposit, southern Mexico. Micrometric scale magnetite was magnetically reduced and divided into distinct size ranges: 85-56 $\mu \mathrm{m}, 56-30 \mu \mathrm{m}, 30-22 \mu \mathrm{m}, 22-15 \mu \mathrm{m}, 15-10 \mu \mathrm{m}, 10-7 \mu \mathrm{m}$ and 7$2 \mu \mathrm{m}$. Nanometric-scale magnetite in the size range $2-14 \mathrm{~nm}$ was identified. The magnetite was characterized by $\mathrm{X}$-ray diffraction, transmitted and reflected light microscope, high-resolution transmission electron microscopy (TEM), high angle annular dark field, Mössbauer spectroscopy and its magnetic properties. Crystallographic identification of nanostructures was performed using high-resolution TEM. Characteristic changes were observed when the particles make the size transition from micro- to nanometric sizes, as follows: (1) frequency-dependent magnetic susceptibility percentage $\left(\chi_{\mathrm{FD}} \%\right)$ measurements show high values $(13 \%)$ for the $2-14 \mathrm{~nm}$ fractions attributed to dominant fractions of superparamagnetic particles; (2) variations of $\chi_{\mathrm{FD}} \%<4.5 \%$ in fractions of 56 $0.2 \mu \mathrm{m}$ occur in association with the presence of microparticles formed by magnetite aggregates of nanoparticles $(<15 \mathrm{~nm})$ embedded in berthierine; (3) Mössbauer spectroscopy results identified a superparamagnetic fraction; (4) nanometric and $0.2-7 \mu \mathrm{m}$ grain size magnetite particles require a magnetic field up to $152 \mathrm{mT}$ to reach saturation during the isothermal remanent magnetization experiment; (5) coercivity and remanent magnetization of the magnetite increase when the particle size decreases, probably due to parallel coupling effects; (6) twomagnetic susceptibility versus temperature experiments of the same 2-14 nm sample show that the reversibility during the second heating is due to the formation of new magnetite nanoparticles and growth of those already present during the first heating process.
\end{abstract}

Key words: Magnetite nanoparticles, berthierine, particle size, magnetic properties, iron-ore deposit, Peña Colorada, Mexico.

\section{Introduction}

Magnetite nanoparticles remain in a particular position of magnetic materials due to their unique physico-chemical properties. As reported by Berquó et al. (2007 and references therein), magnetite shows many fascinating phenomena, such as: (1) charge ordering, mixed valence and metalinsulator transition (Verwey transition); (2) extraordinary biocompatibility for biomedical applications; (3) ultrasmall superparamagnetic (SP) iron oxides for perfusion imaging. Magnetite nanoparticles can be obtained by several methods, including the polyol process, precipitation route, sonochemical synthesis, microemulsion technique and biocompatible coprecipitation (Wu et al., 2007, and references therein).

The Peña Colorada iron-ore deposit is located in the Pacific continental margin of Mexico. It is the principal pellet-

Copyright (c) The Society of Geomagnetism and Earth, Planetary and Space Sciences (SGEPSS); The Seismological Society of Japan; The Volcanological Society of Japan; The Geodetic Society of Japan; The Japanese Society for Planetary Sciences; TERRAPUB. producer in Mexico, supplying an important volume of iron to the world market. The Peña Colorada deposit is, volumetrically, the largest in Mexico, with up to $26-35 \%$ weight Fe. Rock magnetic properties and microscopic detailed studies have been reported by Alva-Valdivia et al. (1996, 2000) and Rivas-Sánchez (2002, 2007), respectively.

The magnetic properties of nanosize fine particle distribution are dominated by effects of the particle size distribution and the behavior of the magnetic anisotropy (BlancoMantecón and O'Grady, 2006). The magnetite grain size distribution is one of the fundamental factors controlling the magnetic properties, and the occurrence of nanoparticles at temperatures typical of near-surface to deep-crustal conditions could provide a new tool by which to define the thermal history of nanoparticle-bearing geologic and planetary materials (Reich et al., 2006).

We report one of the first quantitative results in terms of well-identified grain-size distribution that support the general theoretical basis of frequency-dependent magnetic susceptibility (Dearing et al., 1996). We characterized natu- 


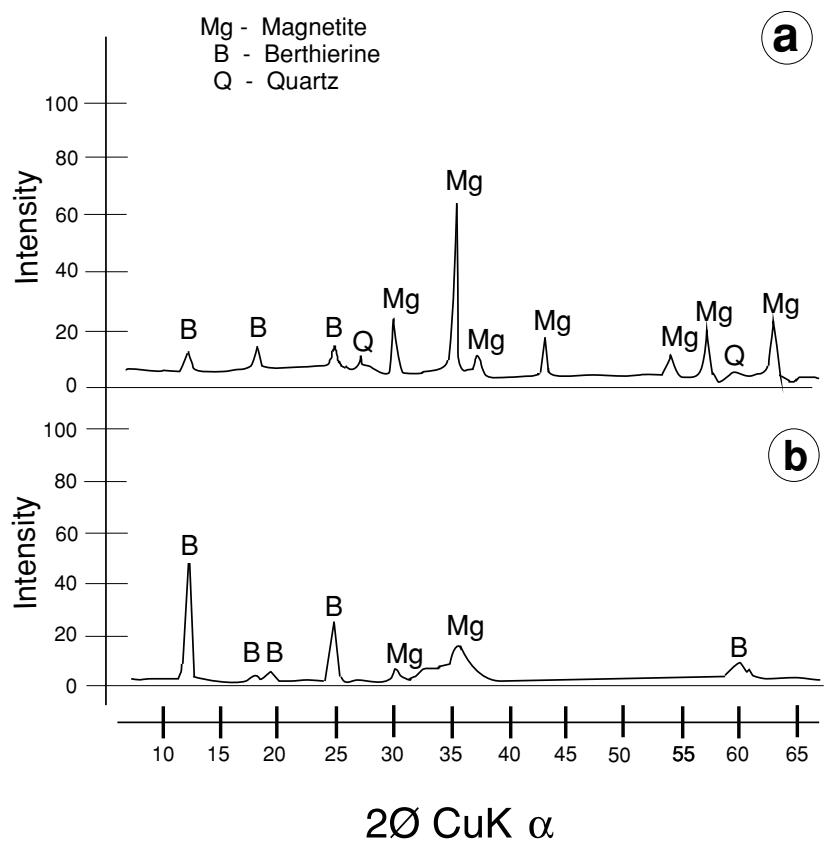

Fig. 1. Magnetite X-ray diffraction pattern: (a) micrometric magnetite; (b) nanometric magnetite.

ral magnetite when particle size makes the transition from micro- to nanometric sizes, observing distinctive changes in the frequency-dependent magnetic susceptibility percentage $\left(\chi_{\mathrm{FD}} \%\right)$ measurements. The values of $\chi_{\mathrm{FD}} \%$ in the mineralized sample of 2-14 nm magnetite nanoparticles and Mössbauer spectroscopy identified a significant proportion of SP particles. The results of a magnetic susceptibility versus temperature experiment of the 2-14 nm sample that was repeated in rapid succession suggest the formation of new magnetite nanoparticles, which is similar to the results obtained by Hirt and Gehring (1991).

\section{Experimental Methods and Sample Descrip- tion}

We prepared a magnetic concentrate from the magnetite ore that was classified in grain sizes using hydro-cycle processes programmed in specific conditions of operation (density, flux source, elutriation time). The samples are "magnetic concentrates" of different grain size obtained using the "hydro-cycle method". These processes are initiated with a base mineral sample, following a sequence of grinding treatment and low-intensity magnetic separation (using a magnetic permanent core). We obtained two sample types: (1) one magnetite concentrate, strongly magnetic, that was constituted mainly by magnetite particles of micrometer scale (sample PC); (2) one moderately magnetic sample, basically constituted by berthierine particles with inclusions of magnetite of nanometer scale (sample A-3n).

The magnetite concentrate was classified in fractions of distinct size ranges (micrometer scale) using hydro-cycle procedures, by an equipment called cyclosizer and subsieve sizer WARMAN model M8. This instrument generates hydro-cycles planned in specific conditions of operation. During each hydro-cycle, a mineral pulp formed by magnetite particles suspended in water circulate continu- ously, following a spiral movement (like a cyclone) that separates, selects and accumulates magnetite particles of specific range size. We obtained six fractions formed by magnetite particles of distinct size range (56-30 $\mu \mathrm{m}, 30-22 \mu \mathrm{m}$, 22-15 $\mu \mathrm{m}, 15-10 \mu \mathrm{m}, 10-7 \mu \mathrm{m}$ and 7-0.2 $\mu \mathrm{m})$. These size fractions and the sample containing magnetite nanoparticles were characterized according to their crystalline, physicochemical and magnetic properties. We used X-ray diffraction (XRD) using a Rigaku diffractometer model GeigerFlex, transmitted and reflected light microscopy, an electron probe X-ray micro-analyzer (EPMA), humid chemical analyses, high-resolution transmission electron microscopy (TEM) with a JEOL 2010 FEG FASTEM, and Mössbauer spectroscopy at room temperature using a Fe standard and ${ }^{57} \mathrm{Co} / \mathrm{Rh}$ radioactive source. Magnetic susceptibility at varying frequencies was measured with a Bartington Instruments MS2 linked to a MS2B dual frequency sensor. We used low frequency ( $\left.\chi_{\mathrm{lf}}=470 \mathrm{~Hz}\right)$ and high-frequency $\left(\chi_{\mathrm{lf}}=4700 \mathrm{~Hz}\right)$ to detect qualitatively the presence of ultrafine grain size carriers of SP behavior. The magnetic susceptibility as a function of temperature was determined by a susceptibilimeter Bartington MS2, with a sensor MS2W coupled to a furnace MS2WFP. To measure the hysteresis parameters and isothermal remanent magnetization (IRM) acquisition and back-field demagnetization curves, we used an alternating field-force gradient magnetometer, Micromag 2900.

\section{Results}

\subsection{XRD and high-resolution TEM}

The first part of our study consisted of a mineralogical characterization by XRD analyses of the micro- and nanometric magnetite magnetic concentrates. The XRD identified magnetite of a micro- and nanometric scale as the sole Fe-oxide present in the sample (Fig. 1). These magnetite particles are closely associated with berthierine and quartz. The micrometric magnetite shows seven well-defined peaks supported by a narrow base in the XRD spectra, indicating a greater degree of crystallinity (Berquó et al., 2007). The opposite is observed for the magnetite nanoparticles, where the peaks are not well defined and are supported by a wide base. Table 1 shows the chemical composition of the fractions classified by grain size. We found magnetite nanoparticles in one sample using high-resolution TEM; these are probably the first images of this type of mineral formed in natural environments. Figure 2 shows a high angle annular dark field (HAADF) image of our semi-spherical magnetite nanoparticles embedded in berthierine. The texture relationship and mineralogical association of magnetite with berthierine is relevant because of their influence on magnetic behavior. The magnetite $2-14 \mathrm{~nm}$ nanoparticles form nanometric size aggregates $(\sim 50-200 \mathrm{~nm})$ which are cemented by berthierine (Rivas-Sánchez et al., 2006). These aggregates also form another group of micrometric particles $(0.2-56 \mu \mathrm{m})$. We measured the magnetic properties in these distinct fractions of magnetite concentrates (microand nanometric sizes). The crystallographic studies using high-resolution TEM confirm the presence of magnetite nanoparticles (Fig. 3), showing a magnetite nanostructure oriented along the [112] direction with interplanar distances 
Table 1. Chemical composition of the magnetite fractions classified by grain size.

\begin{tabular}{ccccccccc}
\hline Sample & $\mathrm{Size}(\mu \mathrm{m})$ & $\mathrm{Fe}$ & $\mathrm{Fe}_{2} \mathrm{O}_{3}$ & $\mathrm{FeO}$ & $\mathrm{Al}_{2} \mathrm{O}_{3}$ & $\mathrm{MgO}$ & $\mathrm{CaO}$ \\
\hline $\mathrm{PC}_{1}$ & $56-30$ & 67.40 & 64.17 & 28.83 & 1.39 & 0.39 & 0.52 \\
$\mathrm{PC}_{2}$ & $30-22$ & 65.99 & 62.88 & 28.21 & 1.89 & 0.50 & 0.73 \\
$\mathrm{PC}_{3}$ & $22-15$ & 63.57 & 60.58 & 27.22 & 2.17 & 0.58 & 0.93 \\
$\mathrm{PC}_{4}$ & $15-10$ & 62.55 & 59.61 & 26.78 & 2.50 & 0.64 & 1.05 \\
$\mathrm{PC}_{5}$ & $10-7$ & 61.95 & 59.04 & 26.52 & 2.83 & 0.70 & 1.26 \\
$\mathrm{PC}_{6}$ & $7-0.2$ & 61.33 & 58.45 & 26.26 & 2.90 & 0.97 & 1.29 \\
$\mathrm{~A}-3 \mathrm{n}$ & $2-14 \mathrm{~nm}$ & 4.13 & 3.93 & 1.78 & 13.03 & 2.24 & 4.18 \\
\hline
\end{tabular}
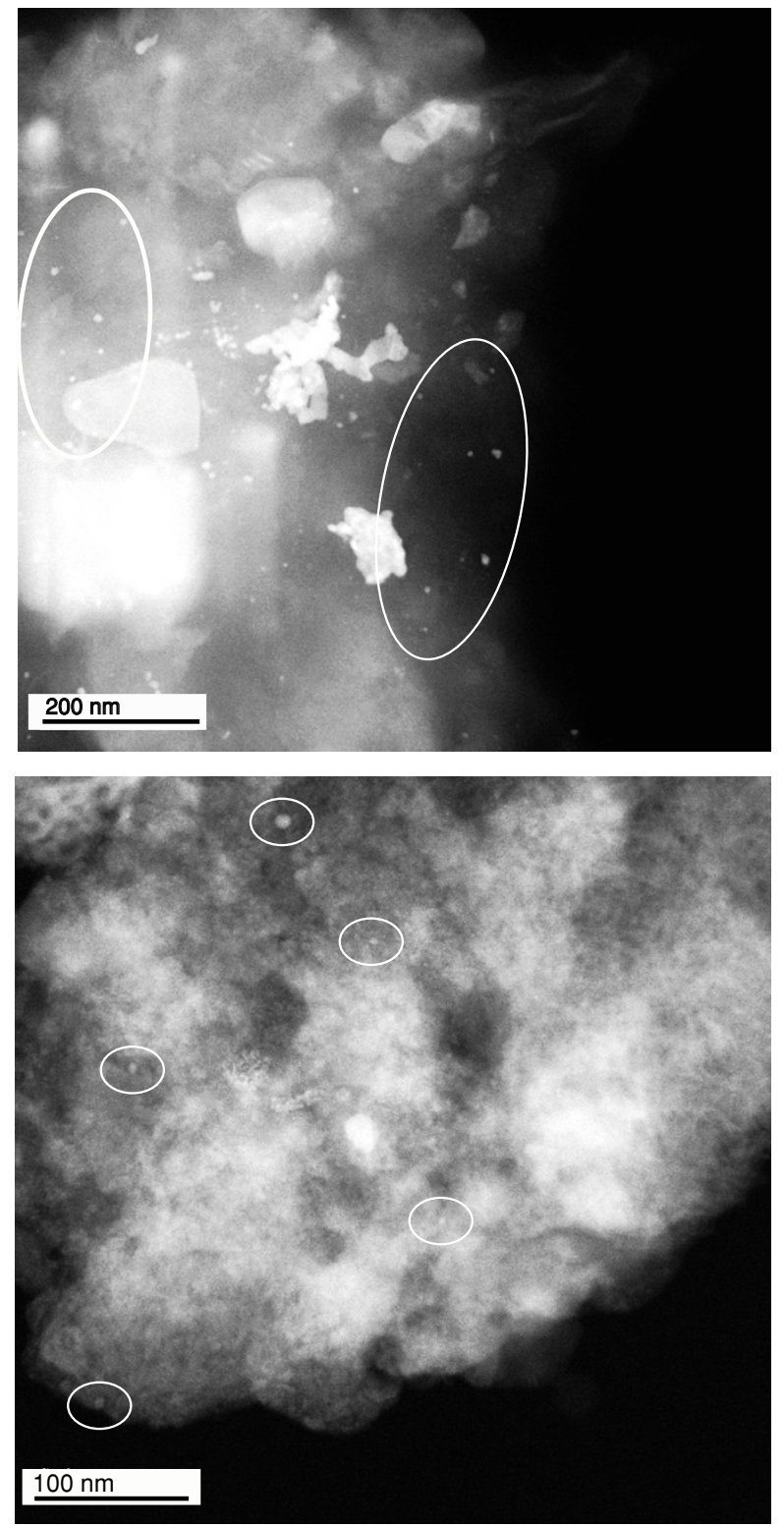

Fig. 2. Magnetite semi-spherical nanoparticles detected by high angular annular dark field (HAADF) homogeneously disseminated in berthierine.

$d_{1}=3.0 \AA$ and $d_{2}=2.54 \AA$. The Fast Fourier Transform (FFT) also confirms the [220] and [311] magnetite crystalline planes corresponding to these distances. The FFT does not show crystalline defects in the nanostructure.

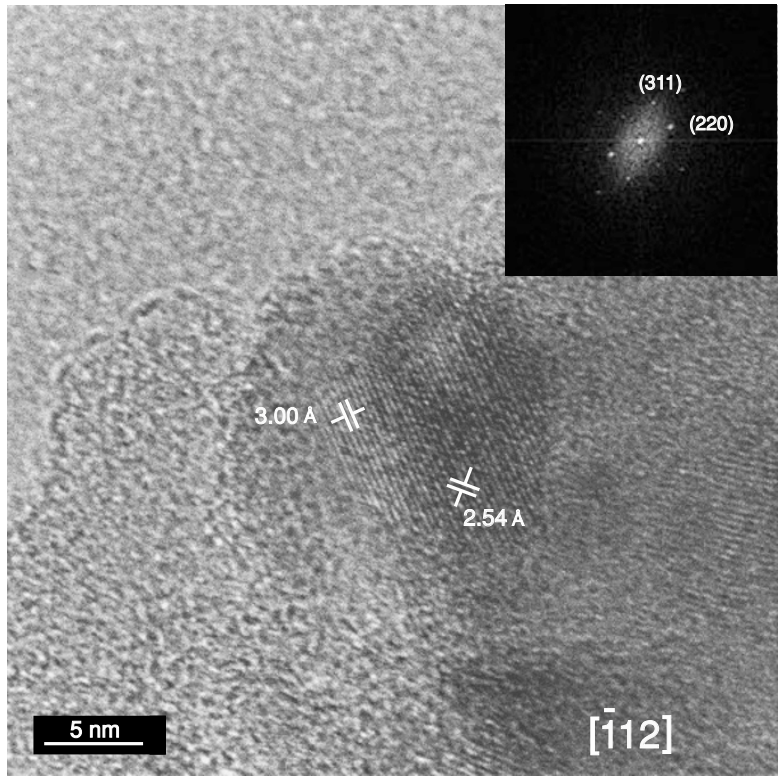

Fig. 3. Magnetite nanostructure image obtained by high-resolution transmission electron microscopy (TEM) (inset box shows the fast Fourier transform (FFT) analysis).

\subsection{Frequency-dependent magnetic susceptibility per- centage $\left(\chi_{\mathrm{FD}} \%\right)$}

The experiments of frequency-dependent magnetic susceptibility $\left(\chi_{\mathrm{FD}} \%\right)$ were interpreted using the model proposed by Dearing et al. (1996) and considering data from Hunt et al. (1995). The magnetic susceptibility is a function of the grain size and magnetic domain state of the sample. The frequency-dependent parameter used was $\chi_{\mathrm{FD}} \%=100$ $\left(\chi_{\text {lf }}-\chi_{\text {hf }}\right) / \chi_{\text {lf }}$. Table 2 shows the results of frequencydependent parameters and the $\chi_{\mathrm{FD}} \%$ of distinct magnetite grain sizes. The magnetite of micrometric fractions ranging from $56-30 \mu \mathrm{m}$ to $7-0.2 \mu \mathrm{m}$ shows low values $(<4.5 \%)$ of $\chi_{\mathrm{FD}} \%$. The sample containing magnetite nanoparticles $(2-14 \mathrm{~nm})$ shows $\chi_{\mathrm{FD}} \%=13 \%$ value.

\subsection{Mössbauer spectroscopy}

The Mössbauer spectroscopy analyses show that the content of magnetite particles has superparamagnetic and ferromagnetic behavior. The micrometric coarse group ranges from 56 to $30 \mu \mathrm{m}$ and the fine group has a size within 7-0.2 $\mu \mathrm{m}$. Figure 4(a), corresponding to the fraction 56$30 \mu \mathrm{m}$, shows Mössbauer spectra typical of magnetite obtained at room temperature and its two magnetic states. The first magnetic state (upper) is consistent with a ferromag- 
Table 2. Frequency dependent parameters and $\chi_{\mathrm{FD}} \%$ of distinct magnetite grain sizes.

\begin{tabular}{ccrrrr}
\hline Sample & \multicolumn{1}{c}{ Size } & \multicolumn{1}{c}{$\chi_{\mathrm{lf}}$} & \multicolumn{1}{c}{$\chi_{\mathrm{hf}}$} & \multicolumn{1}{c}{$\chi_{\mathrm{FD}}$} & \multicolumn{1}{c}{$\chi_{\mathrm{FD}} \%$} \\
\hline $\mathrm{PC}_{1}$ & $56-30 \mu \mathrm{m}$ & 2545.33 & 2436.45 & 108.88 & 4.4 \\
$\mathrm{PC}_{2}$ & $30-22 \mu \mathrm{m}$ & 2809.90 & 2809.27 & 0.63 & 0.02 \\
$\mathrm{PC}_{3}$ & $22-15 \mu \mathrm{m}$ & 3850.41 & 3788.39 & 62.02 & 1.6 \\
$\mathrm{PC}_{4}$ & $15-10 \mu \mathrm{m}$ & 3073.50 & 2941.07 & 132.43 & 4.3 \\
$\mathrm{PC}_{5}$ & $10-7 \mu \mathrm{m}$ & 3587.82 & 3540.98 & 46.84 & 1.3 \\
$\mathrm{PC}_{6}$ & $7-0.2 \mu \mathrm{m}$ & 3993.16 & 3856.32 & 138.84 & 3.4 \\
$\mathrm{~A}-3 \mathrm{n}$ & $2-14 \mathrm{~nm}$ & 32.81 & 28.53 & 4.28 & 13.0 \\
\hline
\end{tabular}

a

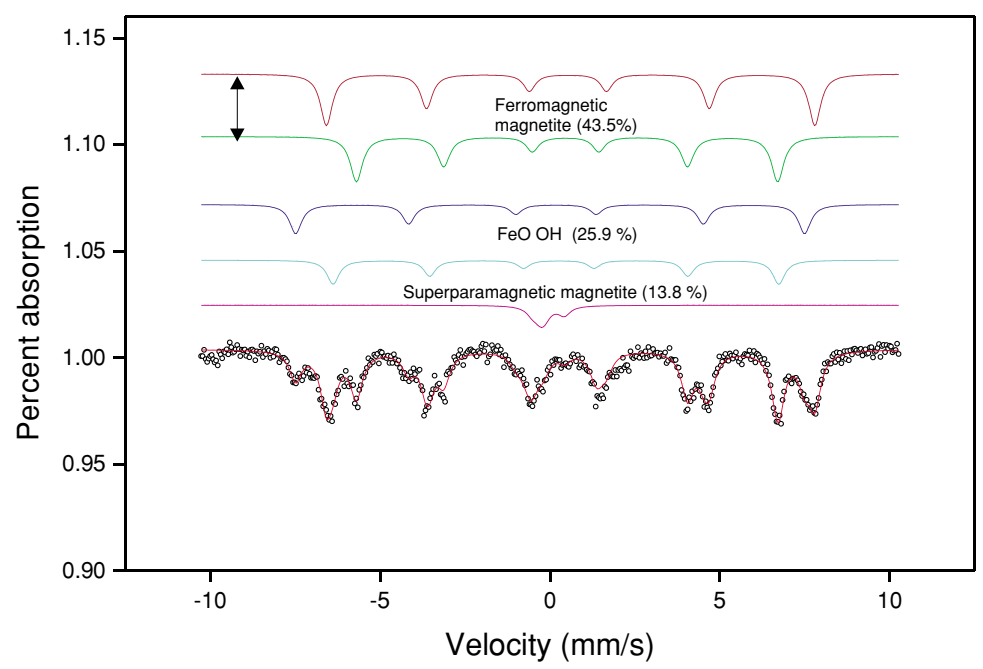

b

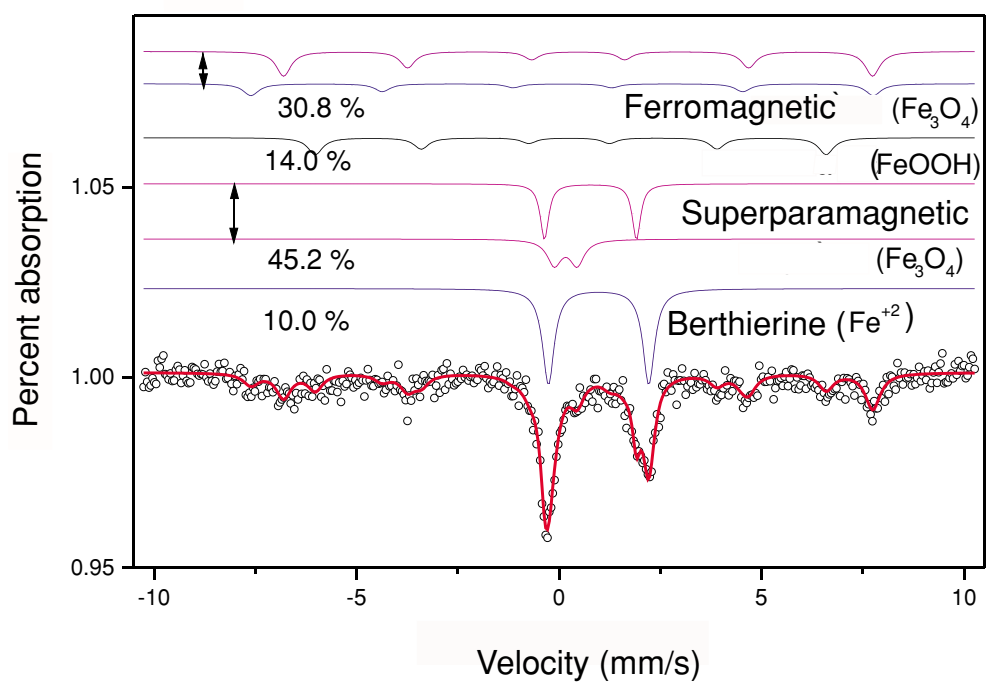

Fig. 4. Mössbauer spectra for magnetite micro- and nanoparticles. (a) Fraction 56-30 $\mu \mathrm{m}$; (b) fraction 7-0.2 $\mu \mathrm{m}$. At the center of the magnetite nanoparticles is the typical doublet of $\mathrm{Fe}^{2+}$ and $\mathrm{Fe}^{3+}$ characteristic of superparamagnetic materials.

netic spectrum formed by six peaks, which corresponds to magnetite nanoparticle aggregates strongly assembled and cemented by berthierine. These aggregates are of micrometer sizes and behave as individual particles, indicating that the $43.5 \%$ of magnetite in this grain-size fraction exhibits ferromagnetic behavior. The fourth spectrum (bottom) is formed by a doublet typical of $\mathrm{Fe}_{3} \mathrm{O}_{4}$ nanophases that cor- responds to $13.8 \%$ of magnetite with superparamagnetic behavior. The third spectrum (middle shows a sextet corresponding to $\mathrm{FeOOH}$ in magnetite-berthierine.

Figure 4(b), corresponding to the $7-0.2 \mu \mathrm{m}$ fraction, shows the Mössbauer spectra of magnetite, also with two magnetic states obtained at room temperature. The magnetite is characterized by a spectrum of ferromagnetic be- 


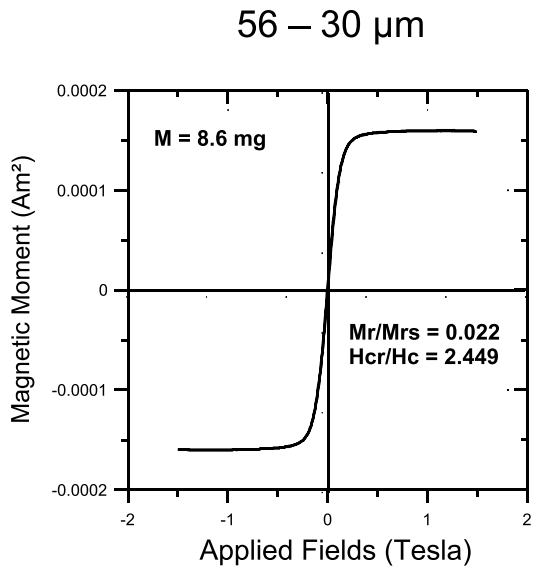

$15-10 \mu \mathrm{m}$
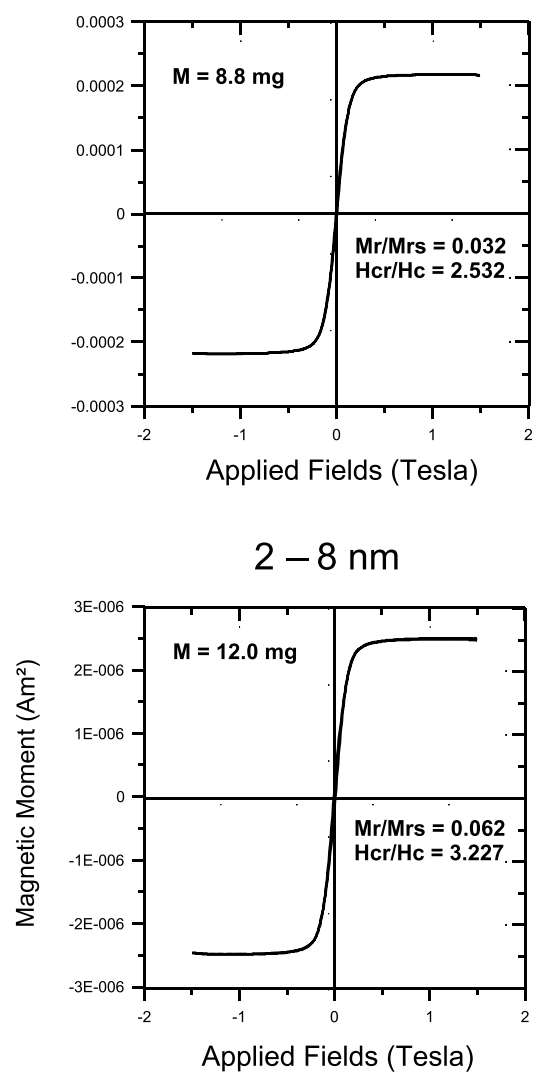

$30-22 \mu \mathrm{m}$

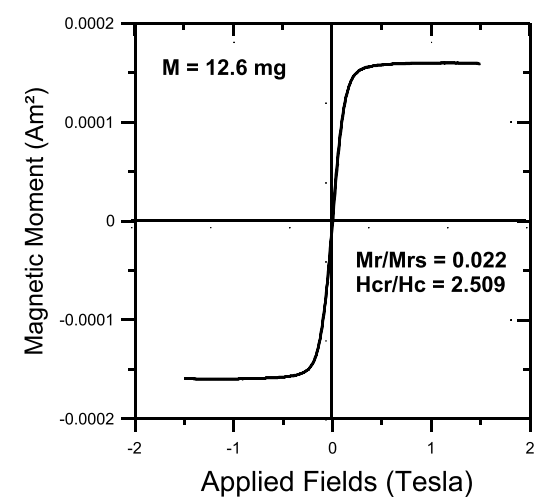

$10-7 \mu \mathrm{m}$
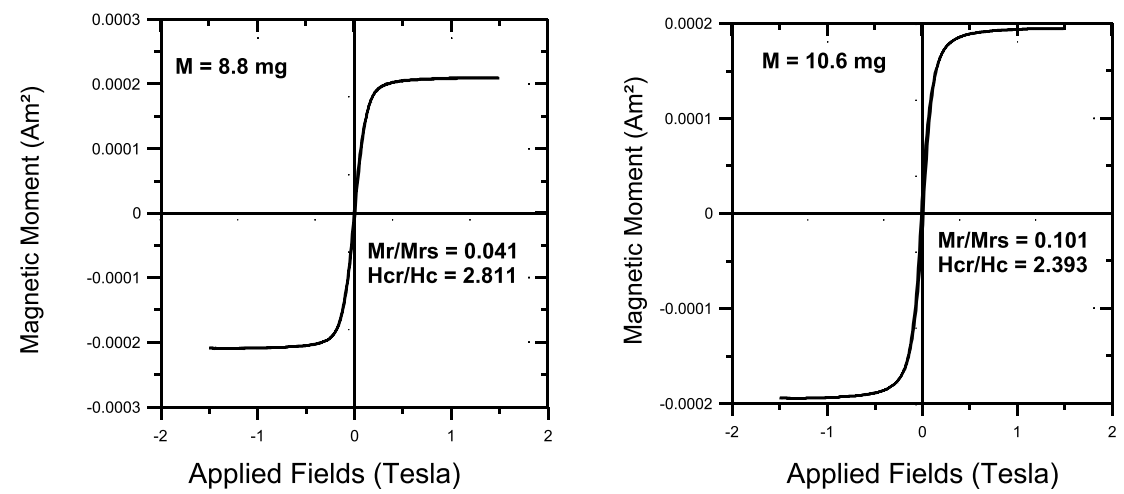

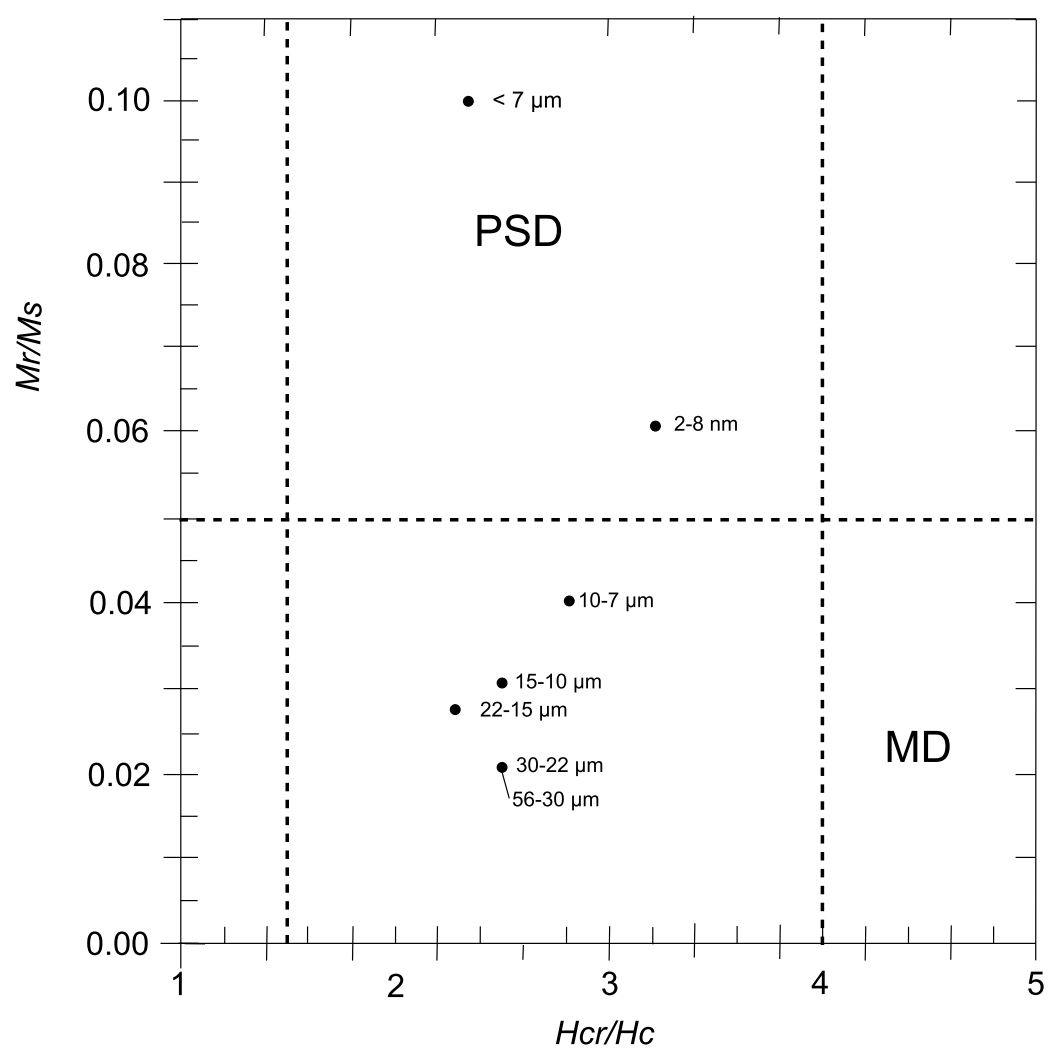

Fig. 5. Magnetite hysteresis cycles for distinct grain size ranges, from micro- to nanometric scale. Day plot is shown at the bottom right. 

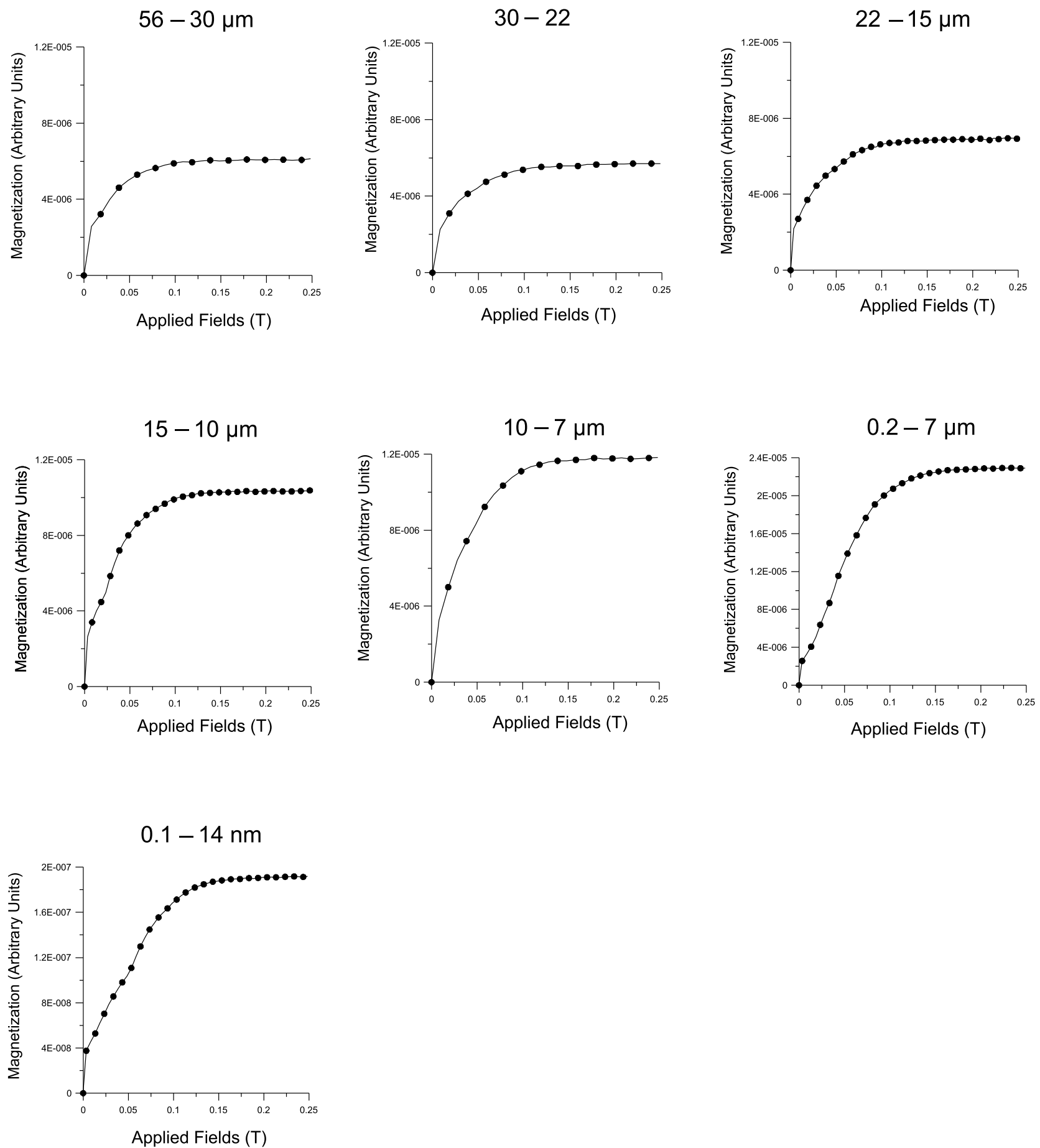

Fig. 6. Magnetite isothermal remanent magnetization parameters for distinct particle size ranges.

havior formed by a sextet (upper) corresponding to $\mathrm{Fe}_{3} \mathrm{O}_{4}$, which is typical of $30.8 \%$ magnetite. Also was identified in a minor proportion $(14.0 \%)$ the ferrimagnetic sextet spectrum of the $\mathrm{FeOOH}$ phase, corresponding to an amorphous substitution phase of berthierine-magnetite. The superparamagnetic magnetite nanoparticles comprise $45.2 \%$ of the sample and are the source of two well-defined double quadrupolar unfolding spectra corresponding to the $\mathrm{Fe}^{2+}$ and $\mathrm{Fe}^{3+}$ species of magnetite, respectively. The doublet represents the fraction of small particles in which longrange magnetic ordering is absent (Xu et al., 2002). These doublets are characteristic of magnetite with SP properties, and their presence supports the results obtained by susceptibility measurements. The last spectrum is a paramagnetic doublet corresponding to the $\mathrm{FeO}$ species of berthierine ( $10 \%$ of this size fraction). Berthierine is typically paramagnetic at room temperature. Hirt and Gehring (1991) found that magnetite is created in heating experiments, and this certainly occurred during a number of hydrothermal processes in our study area. This occurrence can explain the Mössbauer spectrum obtained in our case, which is the emerging of a ferromagnetic phase. 
Table 3. Coercivity and remanence coercivity parameters.

\begin{tabular}{|c|c|c|c|c|c|c|c|c|}
\hline $\begin{array}{l}\text { Size } \\
(\mu \mathrm{m})\end{array}$ & $\begin{array}{c}M_{\mathrm{r}} \\
\left(\mu \mathrm{A} \mathrm{m}^{2}\right)\end{array}$ & $\begin{array}{c}M_{\mathrm{s}} \\
\left(\mu \mathrm{A} \mathrm{m}^{2}\right)\end{array}$ & $M_{\mathrm{r}} / M_{\mathrm{s}}$ & $\begin{array}{c}H_{\mathrm{c}} \\
(\mathrm{mT})\end{array}$ & $\begin{array}{c}H_{\mathrm{cr}} \\
(\mathrm{mT})\end{array}$ & $H_{\mathrm{cr}} / H_{\mathrm{c}}$ & $\begin{array}{c}W \\
(\mathrm{mg})\end{array}$ & $\begin{array}{c}M_{\mathrm{s}} / W \\
\left(\mathrm{~A} \mathrm{~m}^{2} / \mathrm{kg}\right)\end{array}$ \\
\hline $56-30$ & 3.600 & 160.0 & 0.0225 & 2.800 & 6.858 & 2.449 & 8.6 & 18.605 \\
\hline $30-22$ & 3.436 & 152.4 & 0.0225 & 2.918 & 7.322 & 2.509 & 12.6 & 12.095 \\
\hline $22-15$ & 4.349 & 170.2 & 0.0256 & 3.337 & 7.597 & 2.277 & 14.9 & 11.422 \\
\hline $15-10$ & 6.954 & 217.0 & 0.0320 & 3.927 & 9.945 & 2.532 & 8.8 & 24.660 \\
\hline $10-7$ & 8.714 & 209.3 & 0.0416 & 5.147 & 14.470 & 2.811 & 15.7 & 13.331 \\
\hline $7-0.2$ & 19.680 & 194.0 & 0.1014 & 11.090 & 26.540 & 2.393 & 10.6 & 18.301 \\
\hline $2-8 \mathrm{~nm}$ & 154.9 & 2.48 & 0.0625 & 8.180 & 26.400 & 3.227 & 12.0 & 0.207 \\
\hline
\end{tabular}

$W=$ weight.
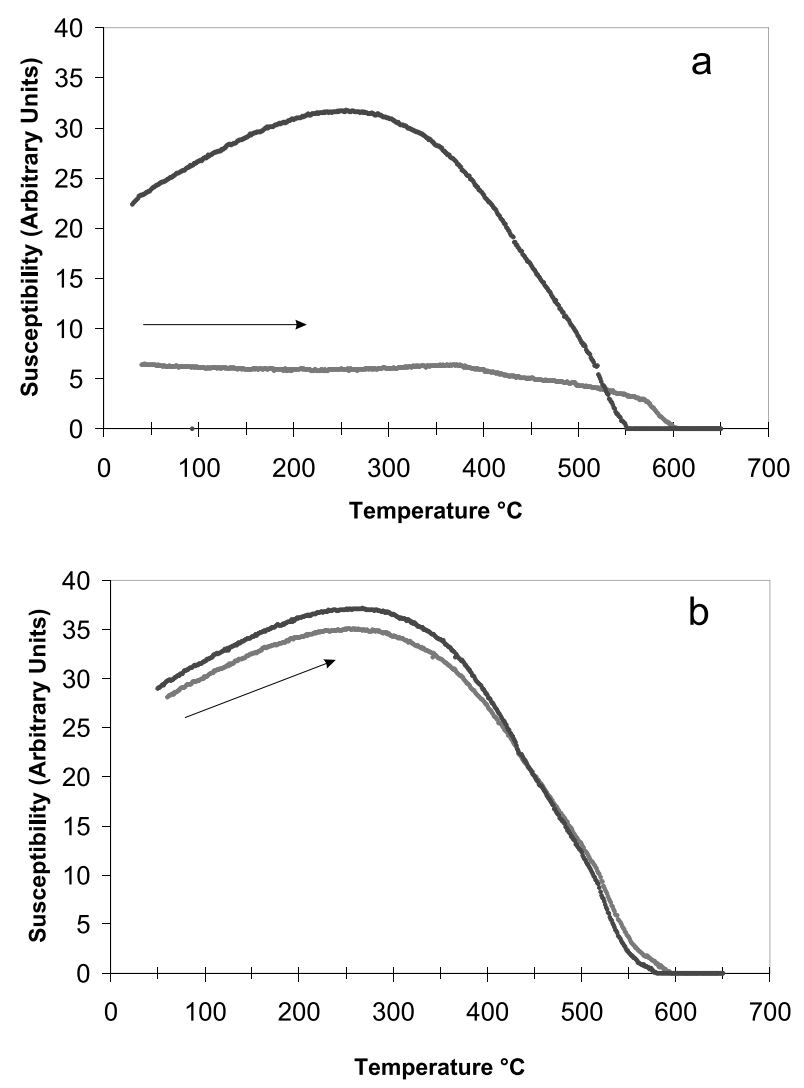

Fig. 7. $k-T$ curves for samples of magnetite nanoparticles: (a) irreversible behavior showing a predominant cooling branch; (b) reversible behavior after repeating the measurement with the same sample for the process in (a). Arrows indicate the heating process.

\subsection{Hysteresis loops and IRM acquisition curves}

Hysteresis loop experiments obtained at room temperature at magnetic field strengths up to $1.5 \mathrm{~T}$ for the distinct fractions of micro- and nanometric particle sizes are shown in Figs. 5 and 6. Table 3 shows the obtained saturation and remanence magnetization, coercivity and remanence coercivity parameters.

The ramp shape close to the origin suggests that all of the obtained hysteresis curves seem to correspond to magnetite. The magnetite samples in the particle size ranging from 56 to $7 \mu \mathrm{m}$ are characterized by a constant increase in the remanence of magnetization versus the saturation magnetization ratio when the particle size is decreasing: $M_{\mathrm{r}} / M_{\mathrm{S}}$ of $0.0225-0.0416$. The magnetite ranging from a particle size of 7 to $0.2 \mu \mathrm{m}$ shows $M_{\mathrm{r}} / M_{\mathrm{s}}$ values of 0.1014 . Similarly, the coercivity $\left(H_{\mathrm{c}}\right)$ of the micrometric samples increases gradually with decreasing particle size. The lowest $H_{\mathrm{c}}$ values $(2.800-3.927 \mathrm{mT})$ occur in the 56-10 $\mu \mathrm{m}$ fractions. Coercivity of the finest fractions (10-7 $\mu \mathrm{m}$ and 7$0.2 \mu \mathrm{m}$ ) increases considerably-from 5.15 to $11.09 \mathrm{mT}$, respectively. The hysteresis parameter plot indicates that almost all values fall in a unique region of the Day plot, similar to the values reported for oceanic dolerites, gabbros and serpentinized peridotites, in being parallel to but below magnetite SD + MD mixing curves (Fig. 5 bottom right; Dunlop, 2002). Dunlop (2002) advised that the interpretation of this new region is not clear.

\subsection{Magnetic susceptibility versus high temperatures $(k-T)$}

We used a mineralized sample containing magnetite nanoparticles $(2-14 \mathrm{~nm})$ for the purpose of characterizing the behavior of the magnetic susceptibility with increasing temperature. Svoboda (1997) found that for ultra-fine particles, the SP contribution of a small concentration has an extraordinary effect on magnetic susceptibility. Figure 7(a) shows that the heating curve of magnetic susceptibility remains almost parallel to the temperature edge up to $360^{\circ} \mathrm{C}$ when, at this point, a slight inflection due to maghemite is produced (due to the scarcity of micrometric magnetite). The curve ends with an abrupt fall after $585^{\circ} \mathrm{C}$, the Curie temperature of magnetite. The most remarkable effect of this $k-T$ experiment occurs during the cooling arm, when a pronounced curve appears between $300^{\circ} \mathrm{C}$ and $200^{\circ} \mathrm{C}$, increasing significantly the magnetic susceptibility. We attribute this effect to the presence of magnetite nanoparticles. After completing this $k-T$ experiment, we repeated it (second heating) using the same sample with the objective of documenting any changes after the first heating. We obtained the graph shown in Fig. 7(b), which confirms the presence of the last formed magnetite as being almost perfectly reversible.

\section{Discussion and Conclusions}

In this study, magnetite was carefully concentrated from coarse to fine particle sizes to study the magnetic behavior of the distinct size ranges under investigation. The behavior of the magnetite nanoparticles was indicative of conspicuous SP properties at room temperature, demonstrat- 


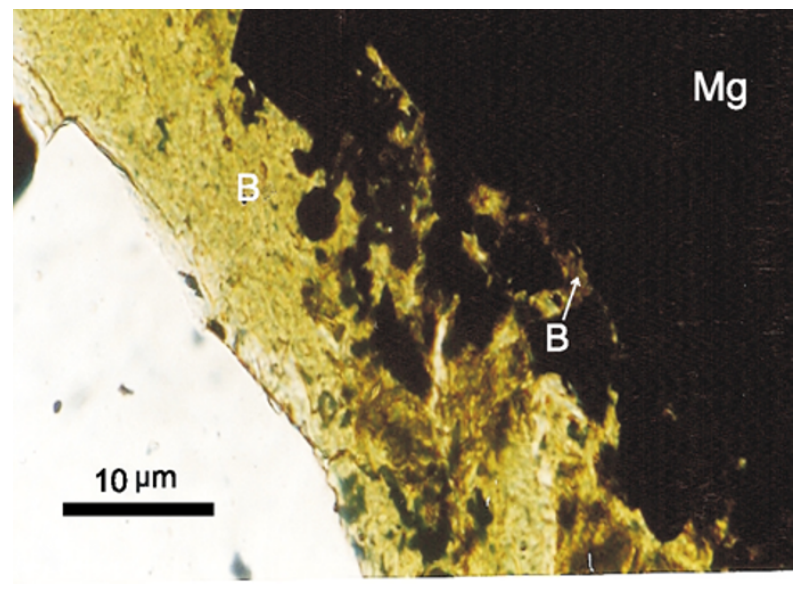

Fig. 8. Magnetite partly replaced by berthierine along its borders, with a color gradation from dark green to brown. Magnetite is botryoidal shape, with a strong corroded border as determined by the substitution effect.

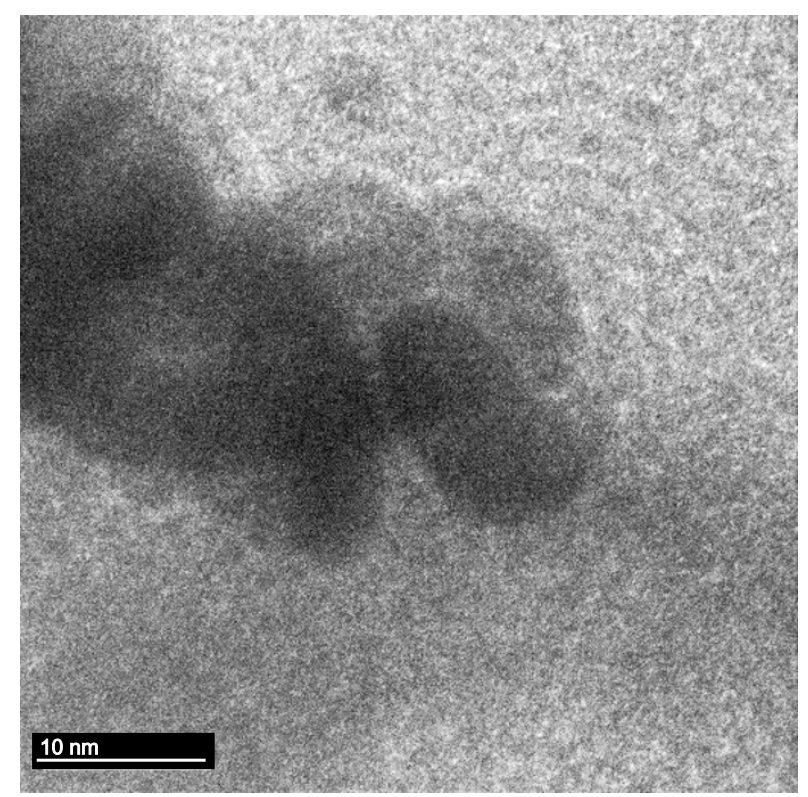

Fig. 9. Clusters of magnetite nanoparticles detected by HAADF disseminated in berthierine.

ing that they are non-homogeneous materials, consisting of a mixture of ferromagnetic and paramagnetic clusters of atoms at the same temperature (Maity and Agrawal, 2007). These results were confirmed using different techniques that included: transmitted and reflected light microscopy, EPMA, high-resolution TEM, HAADF, XRD, Mössbauer spectroscopy, determination of frequency-dependent magnetic susceptibility, hysteresis parameters and temperaturedependent magnetic susceptibility.

The specific behavior of superparamagnetic properties of mineralized iron-ore samples is explained by the presence of magnetite nanoparticles in one sample identified by high-resolution TEM. Figure 2 likely shows the first images of semi-spherical magnetite nanoparticles embedded in berthierine formed in natural environments (HAADF image). The FFT confirms the magnetite crystalline planes corresponding to these distances but does not show crys- talline defects in the nanostructure. The textural relationship and mineralogical association of magnetite with berthierine is relevant because of the influence of this association on magnetic behavior. Berthierine has been fully described in Rivas-Sánchez et al. (2006), and it is important to emphasize that under transmitted light microscopy it shows gradations of dark green to brown coloration along the rounded and corroded borders of the magnetite contact, forming colloform bands intercalated rhythmically like a colloid (Fig. 8). The intercalation of colloids can be attributed to the distinct phases of mineral formation and is related to its chemical composition, as clearly indicated by its formula (Stylianos-Savvas, 1995). The physico-chemical characteristics of berthierine favored the formation of the magnetite nanostructure since the nucleation processes enables magnetite nanocores to grow inside the berthierine, following a spheroidal pattern. Berthierine is formed by a diagenetic process related to a hydrothermal event in a marine environment. The migration of Fe ions from the hydrothermal fluids saturate and enrich the aqueous medium, favoring the precipitation of berthierine. As a result of increasing temperature, in the aqueous medium under reduction conditions, new magnetite nanoparticles and clusters of nanoparticles will form (Fig. 9), possibly facilitated by organic matter or bacteria activity.

The low values $(<4.5 \%)$ obtained from experiments of $\chi_{\mathrm{FD}} \%$ of micrometric fractions of magnetite ranging from $56-30 \mu \mathrm{m}$ to $7-0.2 \mu \mathrm{m}$ can be attributed to the presence of micrometric particles formed mainly by the amalgamation of extremely fine grained magnetite particles $(<0.005 \mu \mathrm{m})$, with the SP fraction being conspicuous. In specific areas of these aggregates, berthierine nanoparticles gave off a small superparamagnetic signal during the susceptibility- versus frequency-dependent experiment. The sample containing magnetite nanoparticles $(2-14 \mathrm{~nm})$ shows $\chi_{\mathrm{FD}} \%=13 \%$, a value that suggests a prevailing proportion $(>70 \%)$ of SP grains $<0.005 \mu \mathrm{m}(5 \mathrm{~nm})$ dominating the sample. Therefore, both samples contain magnetite nanoparticles of superparamagnetic behavior, but with a distinct content of these nanoparticles. We also observed (Table 2) some linearity in the correlation between grains with intermediate $\chi_{\mathrm{FD}} \%$ versus larger $\chi_{\mathrm{FD}}$ values, which could be caused by grains with diameters $<0.01 \mu \mathrm{m}$ behaving collectively as larger grains. These results thus sustain that $\chi_{\mathrm{FD}} \%$ is not limited to values higher than $12 \%$ and that $\chi_{\mathrm{FD}} \%=0$ must not be taken to imply the absence of superparamagnetic grains (Worm and Jackson, 1999).

The Mössbauer results suggest that during the granulometric separation (to obtain our microparticle samples) the major amount of ferromagnetic magnetite was concentrated in the coarsest fraction $(56-30 \mu \mathrm{m})$, with $43.5 \%$ being ferromagnetic microparticles of magnetite and $13.8 \%$ being nanophases of superparamagnetic magnetite. The coercivity was $2.8 \mathrm{mT}$ and the remanent magnetization $3.6 \mu \mathrm{A} \mathrm{m}^{2}$.

In the finest fractions, $7-0.2 \mu \mathrm{m}$, magnetite nanoparticle aggregates are strongly compacted, with $30.8 \%$ being ferromagnetic and $45.2 \%$ being superparamagnetic. Its coercive force increases up to $11.09 \mathrm{mT}$, and the remanent magnetization also increases up to $19.68 \mu \mathrm{A} \mathrm{m}^{2}$. The presence of magnetite microparticles smaller than $7 \mu \mathrm{m}$ and the 
high $\chi_{\mathrm{FD}} \%$ results suggest a preponderance of SP particles (Goya et al., 2003). The fraction that contains magnetite nanoparticles (2-14 $\mathrm{nm}$ ) has $8.18 \mathrm{mT}$ coercivity, a remanent magnetization of close to zero $\left(0.1549 \mu \mathrm{A} \mathrm{m}{ }^{2}\right)$, and a high value of $\chi_{\mathrm{FD}} \%$ (13\%), which corroborates dominance of the superparamagnetic over the nanometric fraction. The nanometric fraction has magnetization and coercivity ratios of 0.0625 and 3.227 , respectively (Table 3 ), which is relevant considering that their volume content is very low $(\sim 2.0 \%)$ in relation to the sample between 0.2 and $7 \mu \mathrm{m}$.

The Mössbauer results confirm the observations obtained by high-resolution TEM-i.e., magnetite microparticles $(0.2-56 \mu \mathrm{m})$ are present in two magnetic states which depend on the textural arrangement, grain size and compaction grade of the magnetite grains and their relation within the berthierine. These results indicate a close relationship with the atomic moment coupling of magnetite nanoparticles: 1) micrometric particles formed by magnetite nanoparticle aggregates are being strongly compacted, promoting coupling between their atomic/magnetic moments and, consequently, the acquisition of ferromagnetic behavior; 2) magnetite nanoparticle aggregates are separated from each other by major amounts of berthierine, which promotes randomness in their atomic/magnetic moments and thereby avoids the exchange forces which result in a superparamagnetic behavior; 3) the ferromagnetic spectrum shown by the $\mathrm{FeOOH}$ molecule could be explained as a berthierine-magnetite substitution phase, developed in a reducing aqueous medium where hydroxyl $(\mathrm{OH}-)$ free radicals interact with the $\mathrm{FeO}$ molecule. In the finest fraction, sample $7-0.2 \mu \mathrm{m}$, there is a significant increase in the aggregate content (fine microparticles) formed by magnetite nanoparticles with superparamagnetic behavior; this is in contrast to the situation in the coarsest fraction sample. This result is probably due to the liberation of magnetite nanoparticles with decreasing nanometric aggregate size, which in turn reduces the exchange forces, thereby avoiding the coupling of magnetic moments between the vicinity atomic moments. Similar interpretations for the magnetic properties of nanoparticles, including their SP relaxation, have been found to depend on the aggregation state due to magnetic coupling being established between surface atoms of neighboring particles (Frandsen and Mørup, 2006).

These results, together with those of $\chi_{\mathrm{FD}} \%$, suggest that the behavior of magnetite microparticles corresponds to that of ultrafine magnetite. Microparticles between 7-0.2 $\mu \mathrm{m}$ are considered to be compact aggregates formed by a significant proportion of SP grains. The textural sort and reaction time for measuring the equipment are closely linked to a decrease in grain size, resulting in a gradual increase of coercivity and remanence. Magnetocrystalline anisotropy (intrinsic property of a ferrimagnet) is independent of grain size (Dunlop and Özdemir, 1997). This anisotropy is mostly due to the energy necessary to deflect the magnetic moment in a single crystal from the easy to the hard direction caused by the interaction of the spin magnetic moment with the crystal lattice (spin-orbit interaction of electrons). The electron orbits are linked to the crystallographic structure, and through their interaction with the spins they cause the latter to prefer to align along well-defined crystallographic axes.
Therefore, there are directions in space in which a magnetic material is easier to magnetize than in others.

Repeated two times magnetic susceptibility versus temperature experiments were performed on the same sample (2-14 nm) in rapid succession. These gave curves that revealed reversibility in the second experiment due to the formation of new magnetite nanoparticles and the likely growth of those already present during the first heating process. This result agrees with that obtained by Novakova et al. (2006).

The behavior of magnetic properties is attributed to their atomic packing. Magnetite nanoparticle agglomeration requires that its magnetic domains display a distinctive behavior, in which SP properties and a major coercive force require a major magnetic field intensity to reach saturation. We concur with Pedreshi et al. (2003) who consider that superparamagnetism in these materials is explained on the basis that thermal energy becomes greater than the anisotropy energy in a single domain material, resulting in a randomly fluctuating magnetic moment.

The magnetic parameters could serve as an indicator of the presence of SP magnetite nanoparticles. Coercivity and remanent magnetization of magnetite increase with decreasing particle size, probably due to parallel coupling effects interacting with antiparallel and uneven atomic moments. A decrease in grain size favors the predominance of a coupling type over other (parallel) effects, resulting in a gradual increase in the coercivity and the remanence due primarily to the magnetocrystalline anisotropy. The magnetite nanoparticles of $2-14 \mathrm{~nm}$ are freely dispersed in berthierine, reaching a remanence close to zero $\left(0.1549 \mu \mathrm{A} \mathrm{m}^{2}\right)$, which suggests the presence of SP natural particles (Maity and Agrawal, 2007).

Acknowledgments. We thank Consorcio Minero Benito Juárez and Peña Colorada for granting access to the ore samples. We also appreciate the laboratory assistance of Luis Rendón, Martín Espinosa and Gabriel Pérez. Our thanks are also extended to G. Aguilar of the Instituto Mexicano del Petroleo by his help in preparing of thin and polished sections. We gratefully acknowledge the comments of three reviewers (Dr. F. Martin, Dr. U. Becker and an anonymous reviewer) and those of Dr. M. Calvo (invited editor). Finally, we thanks the financial support via PAPIITUNAM IN110308 and 102007 and CONACyT research grant 42682F. AG thanks the financial support given by UNAM-PAPIIT IN102007.

\section{References}

Alva-Valdivia, L. M., D. Dunlop, and J. Urrutia-Fucugauchi, Rock magnetic properties of iron ores and hosts rocks from the Peña Colorada mining district, western Mexico, J. Appl. Geophys., 36, 105-122, 1996. Alva-Valdivia, L. M., J. Urrutia-Fucugauchi, A. Goguitchaichvili, and D. Dunlop, Magnetic mineralogy and properties of the Peña Colorada iron ore deposit, Guerrero Terrane: implications for magnetic modeling, $J$. South Am. Earth Sci., 13, 415-428, 2000.

Berquó, T. S., S. K. Banerjee, R. G. Ford, R. L. Peen, and T. Pichler, High crystallinity Si-ferrihydrite: an insight into its Néel temperature and size dependence of magnetic properties, J. Geophys. Res., 112, doi:10.1029/2006JB004583, 2007.

Blanco-Mantecón, M. and K. O'Grady, Interaction and size effects in magnetic nanoparticles, J. Magn. Magn. Mater., 296, 124-133, 2006.

Dearing, J. A., R. J. L. Dann, K. Hay, J. A. Lees, P. J. Loveland, B. A. Maher, and O'Grady, Frequency-dependent susceptibility measurements of environmental materials, Geophys. J. Int., 124, 228-240, 1996.

Dunlop, D. J., Theory and application of the Day plot $\left(\mathrm{M}_{\mathrm{rS}} / \mathrm{M}_{\mathrm{s}}\right.$ versus 
$\left.\mathrm{H}_{\mathrm{cr}} / \mathrm{H}_{\mathrm{c}}\right)$ 2. Application to data for rocks, sediments, and soils, J. Geophys. Res., 107(B3), doi:10.1029/2001JB000487, 2002.

Dunlop, D. and O. Özdemir, Rock-Magnetism, fundamentals and frontiers, 573 pp., Cambrige University Press, 1997.

Frandsen, C. and S. Mørup, Reversible aggregation and magnetic coupling of $\alpha-\mathrm{Fe}_{2} \mathrm{O}_{3}$ nanoparticles, J. Phys.: Condens. Matter., 18, 7079-7084, 2006.

Goya, G. F., T. S. Berquó, F. C. Fonseca, and M. P. Morales, Static and dynamic magnetic properties of spherical nanoparticles, J. Appl. Phys., 94, 3520-3528, 2003.

Hirt, A. M. and A. U. Gehring, Thermal Alteration of the Magnetic Mineralogy in Ferruginous Rocks, J. Geophys. Res., 96(B6), 9947-9953, 1991.

Hunt, C. P., B. M. Moskowitz, and S. K. Banerjee, Magnetic Properties of rocks and minerals, Roks Physics and Phase Relations A. Handbook of Physical Constants, AGU Reference Shelf 3, 1995.

Maity, D. and D. C. Agrawal, Synthesis of iron oxide nanoparticles under oxidizing environment and their stabilization in aqueous and nonaqueous media, J. Magn. Magn. Mater., 308, 46-55, 2007.

Novakova, A. A., E. V. Smirnov, and T. S. Gendler, Magnetic anisotropy in $\mathrm{Fe}_{3} \mathrm{O}_{4}$-PVA nanocomposites as a result of $\mathrm{Fe}_{3} \mathrm{O}_{4}$-nanoparticles chains formation, J. Magn. Magn. Mater., 300, e354-e358, 2006.

Pedreshi, F., J. M. Sturm, J. D. O'Mahony, and C. F. J. Flipse, Magnetic force microscopy and simulations of colloidal iron nanoparticles, $J$. Appl. Phys., 94, 3446-3450, 2003.

Reich, M., S. Utsonomiya, S. E. Kesler, L. Wang, R. C. Ewing, and U. Becker, Thermal behavior of metal nanoparticles in geologic materials, Geology, 34, 1033-1036, 2006.

Rivas-Sánchez, M. L., Caracterización mineralógica y fisicoquímica del mineral de fierro 'normal' y 'amorfo', del yacimiento de Peña Colorada,
Estado de Colima, Unpublished Ms. Sc. Facultad de Ciencias, Universidad Nacional Autonoma de Mexico, 2002.

Rivas-Sánchez, M. L., Nanopartículas de óxidos magneticos formados en ambientes naturales (yacimientos de fierro en América Latina): efecto del tamaño de grano y fases minerales de transformación en sus propiedades magnéticas, Unpublished PhD thesis in Earth Sciences, Instituto de Geofísica, Universidad Nacional Autonoma de Mexico, 2007.

Rivas-Sánchez, M. L., L. M. Alva-Valdivia, J. Arenas-Alatorre, J. UrrutiaFucugauchi, M. Ruíz-Sandoval, and M. A. Ramos-Molina, Berthierine and chamosite hydrothermal: genetic guides in the Peña Colorada magnetite-bearing ore deposit, México, Earth Planets Space, 58, 13891400, 2006.

Svoboda, J., Magnetic methods for the treatment of minerals, Developments in Mineral Processing, 8, Edit. ELSEVIER, 1997.

Stylianos-Savvas, P. A., Atlas of the Textural Patterns of Ore Minerals and Metallogenic Processes, Walter de Grayter \& Co., Berlín, 1995.

Worm, H. U. and M. Jackson, The superparamagnetism of Yucca Mountain Tuff, J. Geophys. Res., 104, 25415-25426, 1999.

Wu, J. H., S. P. Ko, H. L. Liu, S. Kim, J. S. Ju, and Y. K. Kim, Sub $5 \mathrm{~nm}$ magnetite nanoparticles: synthesis, microstructure, and magnetic properties, Mater. Lett., 61, 3124-3129, 2007.

$\mathrm{Xu}, \mathrm{X}$. N., Y. Wolfus, A. Shaulov, Y. Yeshurun, I. Felner, I. Nowik, Y. Koltypin, and A. Gedanken, Annealing study of $\mathrm{Fe}_{2} \mathrm{O}_{3}$ nanoparticles: magnetic size effects and phase transformations, J. Appl. Phys., 91, 4611-4616, 2002.

M. L. Rivas-Sánchez, L. M. Alva-Valdivia (e-mail: lalva@geofisica. unam.mx), J. Arenas-Alatorre, J. Urrutia-Fucugauchi, M. Perrin, A. Goguitchaichvili, M. Ruiz-Sandoval, and M. A. Ramos Molina 